\title{
EDUCAÇÃO FÍSICA E JOGOS ELETRÔNICOS: UMA PROPOSTA EDUCATIVA PARA AS AULAS
}

\section{PHYSICAL EDUCATION AND ELECTRONIC GAMES: AN EDUCATIONAL PROPOSAL FOR THE CLASSES}

\section{EDUCACIÓN FÍSICA Y JUEGOS ELECTRÓNICOS: UNA PROPUESTA EDUCATIVA PARA LAS CLASES}

Javan dos Santos Araújo ${ }^{1}$

https://orcid.org/0000-0002-7997-4179

Wellington Lins de Souza ${ }^{2}$

https://orcid.org/0000-0001-7810-2515

Alesandra Araújo de Souza ${ }^{3}$

https://orcid.org/0000-0003-0303-169X

José Carlos dos Santos ${ }^{4}$

https://orcid.org/0000-0003-0283-0289

Jhonata de Carvalho Ribeiro ${ }^{5}$

https://orcid.org/0000-0002-7294-2617

Aline de Freitas Brito ${ }^{6}$

https://orcid.org/0000-0002-0516-8780

${ }^{1}$ Universidade Federal do Piauí, Teresina, Piauí - Brasil. E-mail: javanaraujo@hotmail.com.

${ }^{2}$ Faculdade de Comunicação, Tecnologia e Turismo de Olinda, Olinda, Pernambuco - Brasil. E-mail: wellingtonlinsdesouza@gmail.com.

3 Universidade Federal do Tocantins, Tocantinópolis, Tocantins - Brasil. E-mail: alesandraaraujodesouza@gmail.com.

4 Universidade Federal do Triângulo Mineiro, Uberaba, Minas Gerais - Brasil. E-mail: jcprofedf@gmail.com.

${ }^{5}$ Universidade Federal do Piauí, Teresina, Piauí - Brasil. E-mail: jhonatacri@hotmail.com.

${ }^{6}$ Universidade de Pernambuco, Recife, Pernambuco - Brasil. E-mail: alineebritoo@gmail.com.

\section{Resumo}

Este estudo verificou se os exergames podem ser considerados uma proposta educativa para a participação dos alunos nas aulas de Educação Física na cidade de Teresina, Piauí. O estudo 
ARAÚJO, J. dos S.; SOUZA, W. L. de; SOUZA, A. A. de; SANTOS, J. C. dos; RIBEIRO, J. de C.; BRITO, A. F. de

caracterizou-se como pesquisa-ação assegurada por dados quantitativos e foi realizado com a participação de 22 alunos do $7^{\circ}$ ano e 36 do $9^{\circ}$ ano de uma escola pública localizada na cidade de Teresina-PI, composto por intervenção em aula e aplicação de questionário não estruturado antes e após a intervenção. A pesquisa aconteceu em três fases: observação e avaliação diagnóstica; planejamento das aulas e intervenção; avaliação das atividades. Após a utilização dos exergames, a estratégia mostrou-se com grande nível de aceitação por parte dos alunos como agente dinamizador e motivador dos conteúdos nas aulas de Educação Física. $\mathrm{O}$ trabalho ainda é limitado devido aos poucos estudos encontrados, mas é evidente que os professores precisam estar abertos ao novo e necessitam de capacitações e estudos sobre o uso das tecnologias digitais, pois elas se encontram presentes no dia a dia de muitos dos seus alunos. Os dados do presente estudo demonstram que, em uma escola da cidade de TeresinaPI, os exergames foram responsáveis pelo aumento significativo da participação dos alunos de $7^{\circ}$ e $9^{\circ}$ anos do ensino fundamental nas aulas de Educação Física. Além disso, os jogos virtuais foram bem aceitos enquanto proposta educativa a ser utilizada durante as aulas.

Palavras-chave: Educação Física. Escola. Jogos de Vídeo. Tecnologia Educacional.

\begin{abstract}
This study verified if exergames can be considered as an educational proposal to the participation of students on Physical Education classes. The study was characterized as action research, guaranteed by quantitative data and was carried out with the participation of 22 students from the 7th grade and 36 from the 9th grade of a public school located in the city of Teresina, Piauí, consisting of classroom intervention and application of a non-structured questionnaire before and after intervention. The research took place in three phases: observation and diagnostic evaluation; lesson planning and intervention; evaluation of activities. After using exergames, the strategy showed a high level of acceptance by the students, as a dynamic and motivating agent for the contents in Physical Education classes. The work is still limited due to the few studies found, but teachers need to be open to the new and need training and studies on the use of digital technologies, as they are present in the daily lives of many of their students. The data from the present study demonstrate that in a school from Teresina-PI, the exergames were responsible for the significative increase of participation of students in Physical Education classes. Furthermore, the virtual games were accepted as educational proposal during classes.
\end{abstract}

Keywords: Physical Education. School. Videogames. Educational Technology.

\title{
Resumen
}

Este estudio verificó si los exergames pueden ser considerados una propuesta educativa para la participación de los estudiantes en las clases de Educación Física de la ciudad de Teresina, Piauí. ${ }^{\circ}$ El estudio se caracterizó como una investigación de acción garantizada por datos cuantitativos y se llevó a cabo con la participación de 22 estudiantes del $7^{\circ}$ año y 36 del 9 año de una escuela pública ubicada en la ciudad de Teresina-PI, que consiste en intervención en la clase y aplicación de un cuestionario no estructurado antes y después de la intervención. La investigación tuvo tres fases: observación y evaluación diagnóstica; planificación de lecciones e intervención; evaluación de actividades. Después de usar los exergames, la estrategia mostró un alto nivel de aceptación por parte de los alumnos como un agente dinámico y motivador para los contenidos en las clases de Educación Física. Los datos del presente estudio demuestran que, en una escuela de la ciudad de Teresina-PI, los 
exergames fueron responsables del aumento significativo de la participación de los estudiantes de $7^{\circ}$ y $9^{\circ}$ grado de la escuela primaria en las clases de Educación Física. Además, se aceptaron bien los juegos virtuales como propuesta educativa para ser utilizada durante las clases.

Palabras clave: Educación Física. Escuela. Videojuegos. Tecnología Educativa.

\section{Introdução}

O ambiente escolar ainda é considerado um dos mais férteis e possíveis de se desenvolverem diversas habilidades, sejam elas artísticas, intelectuais ou motoras (TOKUYOCHI et al., 2008), no entanto evidências científicas destacam que a educação escolar tem enfrentado dificuldades como falta de material e de infraestrutura, além da forma de avaliar o desempenho e a habilidade dos estudantes e a escassez de metodologias inovadoras (ANDRADE; TASSA, 2015). Outras razões são apontadas, como, por exemplo, as dificuldades encontradas pelos professores em relação às práticas pedagógicas e na elaboração de atividades criativas. Outros fatores são a desmotivação e o desinteresse dos alunos quanto à participação nas aulas (TOKUYOCHI et al., 2008). A desmotivação é indicada como um dos principais problemas encontrados na escola (ANDRADE; TASSA, 2015; PIZANI et al., 2016).

Quando essas dificuldades são direcionadas para as aulas de Educação Física escolar, os problemas se tornam ainda maiores, como apontam Tenório e Silva (2015), que diagnosticaram o desinteresse dos alunos de uma escola pública, relacionando-os com a repetição dos conteúdos nas aulas desde os primeiros anos do ensino fundamental junto à exclusão dos menos habilidosos pelos demais colegas de turma.

Na busca por reverter a desmotivação nas aulas, estudos têm destacado a utilização dos jogos eletrônicos como ferramenta metodológica inovadora e interativa no ambiente escolar (PATEL et al., 2009; VAGHETTI; BOTELHO, 2010). Os exergames, termo utilizado atualmente para denominar os jogos em ambiente virtual que se assemelham à prática do exercício físico, foram uma iniciativa das empresas Nintendo Wii, XBOX e Play Station com a finalidade de fornecer à população de adeptos dos jogos de vídeo sedentário uma alternativa que beneficiasse também a saúde física (VAGHETTI; BOTELHO, 2010; VAGHETTI; VIEIRA; BOTELHO, 2016). Inicialmente, os jogos foram utilizados para fins de reabilitação física de pacientes acometidos por insuficiência cardíaca (KLOMPSTRA; JAARSMA; STRÖMBERG, 2014), os quais se encontravam em tratamento para a doença de Parkinson 
ARAÚJO, J. dos S.; SOUZA, W. L. de; SOUZA, A. A. de; SANTOS, J. C. dos; RIBEIRO, J. de C.; BRITO, A. F. de

(ALLEN et al., 2017) ou com fibromialgia. (COLLADO-MATEO et al., 2017a; COLLADOMATEO et al., 2017b). Atualmente, verifica-se que os exergames não somente são utilizados para fins de reabilitação, mas também como uma alternativa para aumento do gasto energético (LANNINGHAM-FOSTER, 2006; GRAVES et al., 2010) e emagrecimento. (BEHMMORAWITZ; LEWALLEN; CHOI, 2010).

$\mathrm{Na}$ Educação Física escolar, os videogames, em especial os exergames, são vistos como uma nova ferramenta pedagógica que possibilita a disseminação dos conhecimentos tecnológicos, proporcionando ganhos de ordem sensorial e motora, além de auxiliarem na promoção da atividade física, propiciada pelo mecanismo de realidade virtual (VAGHETTI; BOTELHO, 2010; VAGHETTI; VIEIRA; BOTELHO, 2016). Um impasse importante ainda encontrado na introdução dos jogos eletrônicos nas aulas de Educação Física escolar pelos professores é que a maioria das instituições de ensino superior ainda não oferta, em suas grades curriculares, disciplinas que expliquem e demonstrem a importância desse recurso. Somado a isso, Gomes (2014) nos mostra que o jogo eletrônico, embora seja familiar e consolidado para crianças e adolescentes, é um grande desconhecido para a maior parte dos adultos.

Mediante os pressupostos apresentados e levando em consideração a importância da Educação Física escolar, elegemos a seguinte questão norteadora: a utilização dos jogos eletrônicos nas aulas de Educação Física poderá provocar uma adesão maior por parte dos alunos se os exergames forem utilizados como estratégia de proposta de conteúdo?

Hayes e Silberman (2007) revelam que, quando os exergames foram inseridos nas salas de aulas tradicionais, houve uma recepção muito boa por parte dos alunos por estarem vendo algo novo, diferente dos conteúdos que eram apresentados no currículo padrão. Lieberman (2006) realizou um estudo com 20 escolas da Virginia Ocidental (EUA) sobre a utilização do exergame Dance Dance Revolution (DDR) em aulas de Educação Física e Saúde. Nesse estudo, o autor afirma que alguns jovens perderam cerca de $4 \mathrm{~kg}$ após o uso do DDR na escola. O estado de West Virginia implementou, nas suas 765 escolas públicas, o exergame DDR no currículo da Educação Física escolar por ser uma excelente ferramenta para trabalhar habilidades motoras e cognitivas e um recurso contra a obesidade infantil.

Por a temática ainda carecer de afirmação científica e apresentar desconhecimento por parte de muitos escolares, em especial no Brasil, o objetivo da presente investigação foi 
verificar se os exergames podem ser considerados uma proposta educativa para a participação dos alunos nas aulas de Educação Física na cidade de Teresina-PI.

\section{Metodologia}

O presente estudo teve início a partir do parecer favorável do Comitê de Ética de Pesquisa com Seres Humanos da Universidade Federal do Piauí (CEP/UFPI), sob o Parecer no 1.607.562, caracterizando-se como uma pesquisa-ação (TRIPP, 2005) com apoio em dados quantitativos. (BARBIER, 2007).

Tripp (2005, p. 447) revela que a "pesquisa-ação é uma forma de investigação-ação que utiliza técnicas de pesquisa consagradas para informar a ação que se decide tomar para melhorar a prática [...]”. Conforme o autor, esse tipo de pesquisa se concretiza a partir de um ciclo que consiste na fase exploratória/avaliação diagnóstica, planejamento e implementação das atividades, avaliação da mudança para melhorar a prática, assim como o aprendizado ocorrido durante o processo (TRIPP, 2005).

A pesquisa foi realizada em escola pública durante uma das etapas da disciplina de Estágio Supervisionado III do curso de Licenciatura em Educação Física da Universidade Federal do Piauí. Participaram do estudo alunos de ambos os gêneros, sendo 22 do $7^{\circ}$ ano e 36 do $9^{\circ}$ ano do turno da manhã do ensino fundamental.

O desenvolvimento da pesquisa se deu em três fases: "observação e avaliação diagnóstica", "planejamento das aulas e intervenção" e "avaliação das atividades".

\subsection{Observação e avaliação diagnóstica}

O primeiro momento compreendeu a fase de observação, visando a compreender todo o contexto da aula, como as atividades desenvolvidas e o comportamento tanto dos alunos como do professor, juntamente com a aplicação de questionário diagnóstico com as seguintes questões: 1- Você participa das aulas de Educação Física?; 2- Você gosta dos conteúdos das aulas de Educação Física?; 3- Você gostaria de ter aulas com jogos eletrônicos?; 4- Você conhece os exergames?; 5- Quais atividades você gostaria que as aulas de Educação Física tivessem? 
ARAÚJO, J. dos S.; SOUZA, W. L. de; SOUZA, A. A. de; SANTOS, J. C. dos; RIBEIRO, J. de C.; BRITO, A. F. de

\subsection{Planejamento das aulas e intervenção}

Nessa fase foi elaborada, em conjunto com a professora de Educação Física da turma, um plano de atividades composto por sete aulas. No terceiro momento aplicamos um novo questionário com o intuito de saber se os exergames poderiam ser utilizados nas aulas de Educação Física como ferramenta de motivação aplicável. Como instrumento foi utilizado, nas aulas, um projetor multimídia, o console XBOX 360 Kinect e o game Kinect Sports nas modalidades esportivas: voleibol, boxe, tênis de mesa, boliche e atletismo.

A abordagem escolhida para se trabalharem todas as atividades foram os Parâmetros Curriculares Nacionais (1997), em especial o primeiro grande bloco de conteúdos, que inclui os esportes, as lutas, os jogos e as ginásticas, os quais devem ser abordados por suas diversas intenções e manifestações, organizados de maneira adequada a cada nível de ensino.

O planejamento pedagógico nas quatro semanas de aula ou, mais especificamente, em cada dia de estágio supervisionado na Educação Física, pode ser verificado no Quadro 1 e na Tabela 1.

Quadro 1 - Planejamento pedagógico das atividades do estágio supervisionado no ensino fundamental II.

\begin{tabular}{|c|c|c|c|c|}
\hline Semana & Objetivos & Conteúdo & Abordagem e Atividade & Avaliação \\
\hline $1^{\mathrm{a}}$ & $\begin{array}{l}\text { Desenvolver brincadeiras afim de } \\
\text { promover a interação social. }\end{array}$ & Jogos & $\begin{array}{l}\text {-Abordagem pedagógica (PCN, } \\
\text { 1997) Marcelo Jabu e Caio } \\
\text { Costa. } \\
\text { - Campeonato de queimada }\end{array}$ & $\begin{array}{l}\text { Formativa: } \\
\text { Observar o empenho do } \\
\text { aluno durante o jogo, } \\
\text { verificando a obediência às } \\
\text { regras. }\end{array}$ \\
\hline $2^{\mathrm{a}}$ & $\begin{array}{l}\text { Conhecer as várias formas de se } \\
\text { jogar os exergames }\end{array}$ & Jogos & $\begin{array}{l}\text {-Abordagem Pedagógica (PCN, } \\
\text { 1997) Marcelo Jabu e Caio } \\
\text { Costa. } \\
\text {-Exergames: kinect sport }\end{array}$ & $\begin{array}{l}\text { Diagnostica e Formativa: } \\
\text { verificar ao final da } \\
\text { atividade se os alunos } \\
\text { conseguiram compreender e } \\
\text { executar a prática. }\end{array}$ \\
\hline $3^{\mathrm{a}}$ & $\begin{array}{l}\text { Desenvolver atividades que leve } \\
\text { o aluno ao aprendizado do } \\
\text { fundamento básico do basquete }\end{array}$ & Esportes & $\begin{array}{l}\text {-Abordagem Pedagógica PCNs } \\
\text { (1997) Marcelo Jabu e Caio } \\
\text { Costa. } \\
\text {-Basquete-fundamentos }\end{array}$ & $\begin{array}{l}\text { A avaliação será formativa } \\
\text { no qual ocorrerá ao longo do } \\
\text { processo de ensino- } \\
\text { aprendizagem. }\end{array}$ \\
\hline $4^{\mathrm{a}}$ & $\begin{array}{l}\text { Desenvolver a prática desportiva, } \\
\text { a amizade, a coletividade e a } \\
\text { diversão, além da integração } \\
\text { entre os alunos. }\end{array}$ & Esportes & $\begin{array}{l}\text { - Abordagem Pedagógica PCNs } \\
\text { (1997) Marcelo Jabu e Caio } \\
\text { Costa. } \\
\text { - Projeto interclasses futsal }\end{array}$ & $\begin{array}{l}\text { Formativa: verificar se tudo } \\
\text { que foi proposto durante a } \\
\text { aula pelo professor estava } \\
\text { sendo atingido durante o } \\
\text { processo de ensino } \\
\text { aprendizagem. }\end{array}$ \\
\hline
\end{tabular}


Legenda: PCNs, parâmetros curriculares nacionais.

Fonte: Dados da pesquisa.

Tabela 1 - Atividade das 10 aulas

\begin{tabular}{ccc}
\hline Data & Horário & Conteúdo da Aula \\
\hline $13 / 04 / 2016$ & $13 \mathrm{~h} 20 \mathrm{~min}$ às $17 \mathrm{~h} 40 \mathrm{~min}$ & Observação \\
\hline $19 / 04 / 2016$ & $13 \mathrm{~h} 20 \mathrm{~min}$ às $17 \mathrm{~h} 40 \mathrm{~min}$ & Observação \\
\hline $26 / 04 / 2016$ & $13 \mathrm{~h} 20 \mathrm{~min}$ às $17 \mathrm{~h} 40 \mathrm{~min}$ & Observação \\
\hline $03 / 05 / 2016$ & $13 \mathrm{~h} 20 \mathrm{~min}$ às $17 \mathrm{~h} 40 \mathrm{~min}$ & Campeonato de Queimada \\
\hline $10 / 05 / 2016$ & $13 \mathrm{~h} 20 \mathrm{~min}$ às $17 \mathrm{~h} 40 \mathrm{~min}$ & Fundamentos básicos do basquete \\
\hline $17 / 05 / 2016$ & $13 \mathrm{~h} 20 \mathrm{~min}$ às $17 \mathrm{~h} 40 \mathrm{~min}$ & Fundamentos básicos do basquete \\
\hline $24 / 05 / 2016$ & $13 \mathrm{~h} 20 \mathrm{~min}$ às $17 \mathrm{~h} 40 \mathrm{~min}$ & Exergames: jogos eletrônicos \\
\hline $31 / 05 / 2016$ & $13 \mathrm{~h} 20 \mathrm{~min}$ às $17 \mathrm{~h} 40 \mathrm{~min}$ & Exergames: jogos eletrônicos \\
\hline $07 / 06 / 2016$ & $13 \mathrm{~h} 20 \mathrm{~min}$ às $17 \mathrm{~h} 40 \mathrm{~min}$ & Interclasse de futsal \\
\hline $14 / 06 / 2016$ & $13 \mathrm{~h} 20 \mathrm{~min}$ às $17 \mathrm{~h} 40 \mathrm{~min}$ & Olimpiada de matemática \\
\hline
\end{tabular}

Fonte: Dados da pesquisa.

Na primeira semana da regência, realizamos a atividade de queimada, a qual estava no planejamento da professora. A metodologia usada para essa atividade foi um campeonato disputado entre as turmas do $6^{\circ}$ ao $9^{\circ}$ ano, mas observou-se que muitos alunos não participavam por se tratar de uma atividade que realizavam em todas as aulas. O que pode ser observado é que o jogo era realizado só por jogar, sem qualquer significância.

$\mathrm{Na}$ segunda e terceira semanas, o tema foi esportes e a atividade desenvolvida foi o basquete. A aula iniciou-se na sala, onde fizemos uma breve explicação de como a aula se desenvolveria. No primeiro momento, fizemos um breve histórico sobre a modalidade e em seguida fomos para a quadra, onde iniciamos com algumas atividades abordando os fundamentos básicos. De início, alguns não se envolveram com a atividade, mas, por meio de algumas atividades lúdicas e uma pequena disputa no final da aula, conseguimos que a maioria dos alunos participasse da aula.

$\mathrm{Na}$ quarta e quinta semana trabalhamos com o exergame, uma atividade até o momento desconhecida para a maioria dos alunos. Em conversa com a direção da escola, o 
ARAÚJO, J. dos S.; SOUZA, W. L. de; SOUZA, A. A. de; SANTOS, J. C. dos; RIBEIRO, J. de C.; BRITO, A. F. de

pedagogo e a professora, sugerimos que a atividade fosse desenvolvida em uma única sala. $\mathrm{O}$ jogo utilizado foi o Kinect Sports nas modalidades esportivas, boxe, tênis de mesa e atletismo. Iniciamos a aula com a turma do $9^{\circ}$ ano e foi feita uma demonstração básica do funcionamento do jogo aos participantes.

Na sexta semana, a atividade desenvolvida foi um interclasse de futsal, no qual nos reunimos com os alunos e fizemos um sorteio dos times que se inscreveram. O objetivo do torneio foi proporcionar aos estudantes a prática do futsal de forma recreativa e competitiva e para que eles pudessem ter contato com as regras desse esporte, pois as aulas dessa modalidade ministradas pela professora eram práticas, sem levar em conta as regras. A falta de vivências com as regras ficou bem nítida quando da competição.

$\mathrm{Na}$ sétima semana, os alunos participaram de uma olimpíada de matemática como atividade antecipadamente constante no calendário pedagógico da escola. Essa atividade serviu convenientemente como washout para os efeitos de nossa intervenção propriamente dita, buscando confirmar a cronicidade dos resultados coletados pós-aulas com exergames.

\subsection{Avaliação das atividades}

Essa fase pode ser expressa pelo texto descritivo da sessão "Resultados" e pela discussão da sessão "Discussão".

\section{Resultados}

No gráfico da Figura 1 estão apresentados os resultados encontrados após a resposta à primeira pergunta do questionário não estruturado: "Você participa das aulas de Educação Física?". Observa-se que todos os alunos do $7^{\circ}$ ano responderam positivamente tanto no período pré (painel A) quanto no pós-intervenção pedagógica (painel B). Enquanto isso, 74 \% dos alunos do $9^{\circ}$ ano afirmaram participação nas aulas antes da intervenção pedagógica (painel A), sendo esses valores modificados para $88 \%$ após a intervenção no estágio supervisionado (painel B). 
Figura 1 - Quantitativo de alunos que responderam pré e pós-intervenção pedagógica se participavam das aulas de Educação Física.
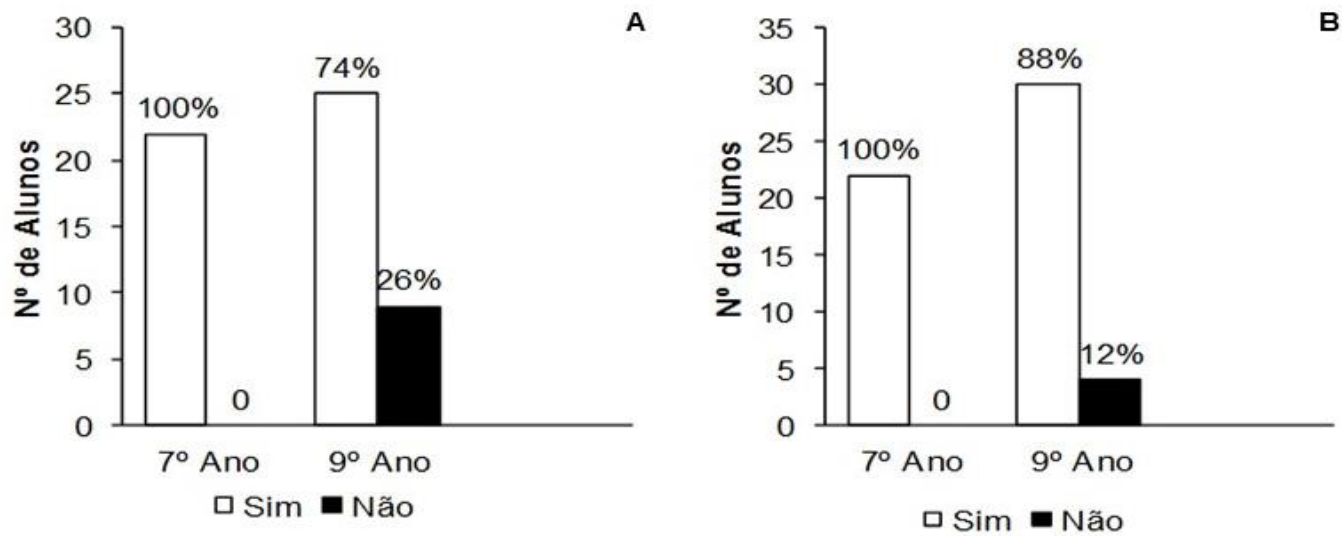

Período pré (painel A) e pós-intervenção pedagógica (painel B). Os dados estão apresentados como valores percentuais.

Fonte: Autoria própria.

Na Figura 2 estão apresentados os resultados encontrados após a resposta à segunda pergunta do questionário não estruturado: "Você gosta dos conteúdos das aulas de Educação Física?". Observa-se que todos os alunos do $7^{\circ}$ ano responderam positivamente tanto no período pré (painel A) quanto no pós-intervenção pedagógica (painel B). Enquanto isso, 97\% dos alunos do $9^{\circ}$ ano afirmaram participação nas aulas antes da intervenção pedagógica (painel A), sendo esses valores modificados para $100 \%$ após o estágio supervisionado (painel B).

Figura 2 - Quantitativo de alunos que responderam pré e pós-intervenção pedagógica se gostavam dos conteúdos das aulas de Educação Física.
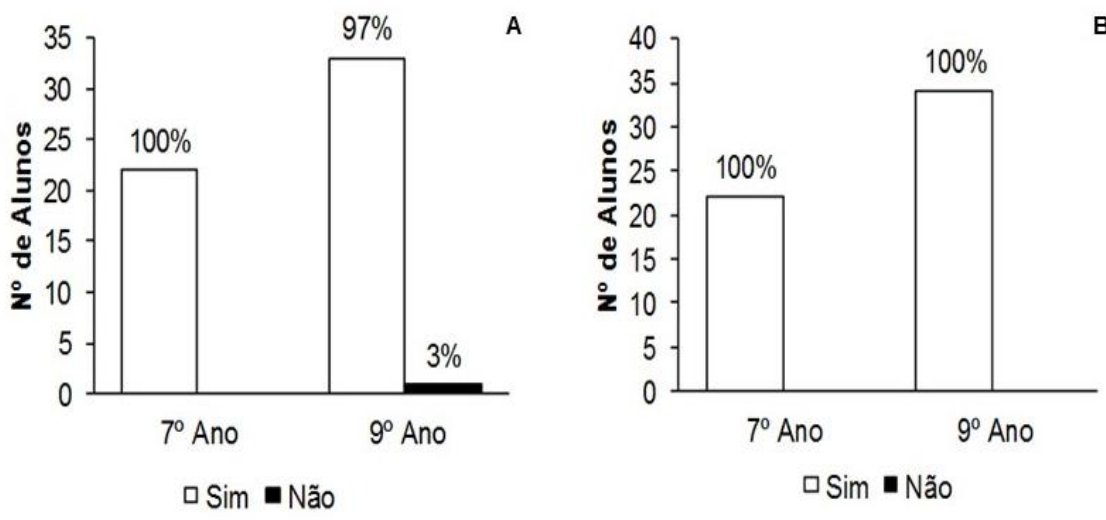
ARAÚJO, J. dos S.; SOUZA, W. L. de; SOUZA, A. A. de; SANTOS, J. C. dos; RIBEIRO, J. de C.; BRITO, A. F. de

\section{Períodos pré (painel A) e pós-intervenção pedagógica (painel B). Os dados estão apresentados como valores} percentuais.

Fonte: Dados da pesquisa.

Na Figura 3 estão apresentados os resultados encontrados após a resposta à terceira pergunta do questionário não estruturado: "Você gostaria de ter aulas com jogos eletrônicos?". Observa-se que $91 \%$ dos alunos do $7^{\circ}$ ano responderam positivamente no período pré-intervenção pedagógica (painel A) e, após a intervenção, durante o estágio supervisionado, $100 \%$ referiram ter gostado das aulas. Quanto ao $9^{\circ}$ ano, no período préintervenção, 97\% dos alunos afirmaram que gostariam de ter aulas com jogos eletrônicos e, logo após o estágio supervisionado, $100 \%$ deles disseram ter também gostado das aulas com os exergames (painel B).

Figura 3 - Quantitativo de alunos que responderam pré e pós-intervenção pedagógica se gostariam de ter aulas com jogos eletrônicos.
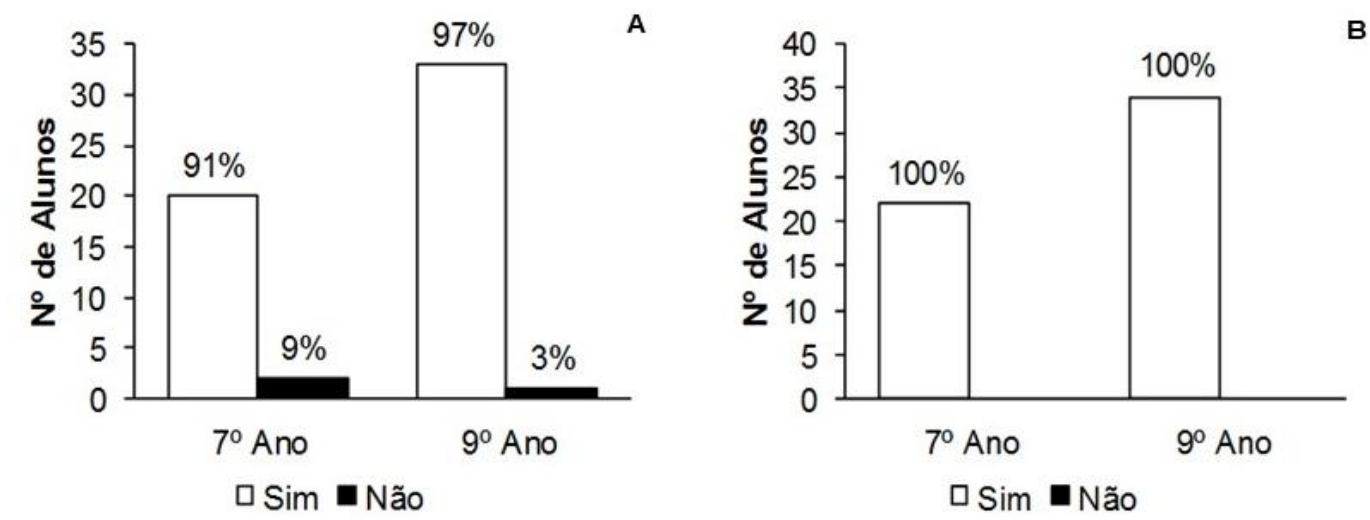

Período pré (painel A) e pós-intervenção pedagógica (painel B). Os dados estão apresentados como valores percentuais.

Fonte: Dados pesquisa.

Na Figura 4 estão apresentados os resultados encontrados após a resposta à quarta pergunta do questionário não estruturado: "Você conhece exergames?". Observa-se que apenas $32 \%$ dos alunos do $7^{\circ}$ ano responderam positivamente no período pré-intervenção pedagógica (painel A) e, após a intervenção, todos tinham conhecimento dos exergames. De modo similar, o verificou-se que, no $9^{\circ}$ ano, no período pré-intervenção, apenas $38 \%$ dos 
alunos afirmavam conhecer os exergames, porém esse valor sofreu modificação para 100\% após o estágio supervisionado (painel B).

Figura 4 - Quantitativo de alunos que responderam pré e pós-intervenção pedagógica se conheciam exergames.
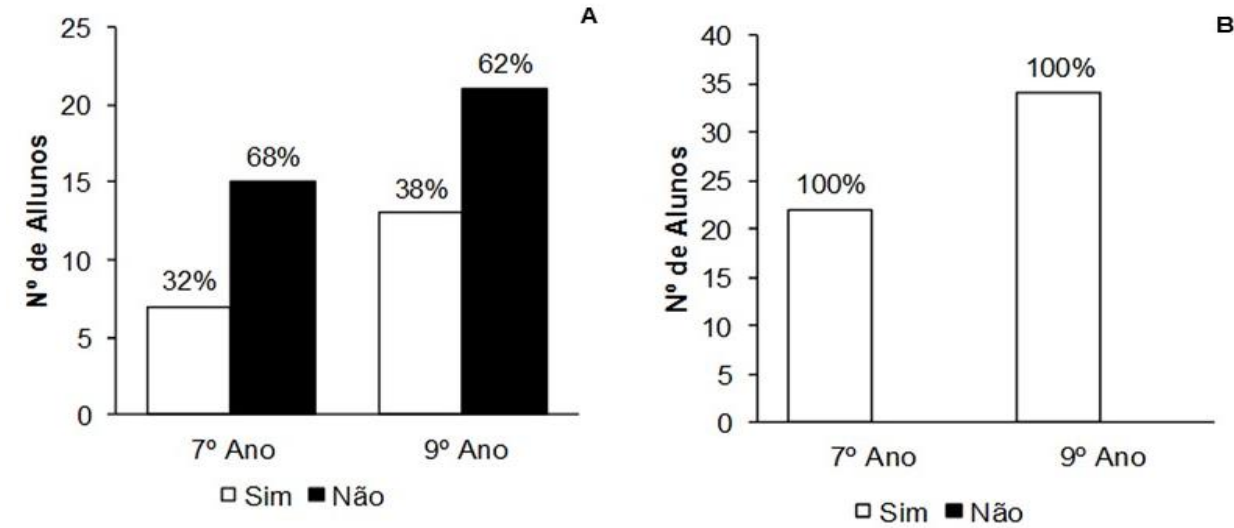

Períodos pré (painel A) e pós-intervenção pedagógica (painel B). Os dados estão apresentados como valores percentuais.

Fonte: Dados pesquisa.

Na Figura 5 estão apresentados os resultados encontrados após a resposta à quinta pergunta do questionário não estruturado: "Quais atividades você gostaria que as aulas de Educação Física tivessem?” Antes da intervenção pedagógica (painel A), os alunos do $7^{\circ}$ e $9^{\circ}$ anos tinham por preferência os conteúdos relacionados com o basquetebol. Depois do estágio supervisionado (painel B), todos os alunos demonstraram maior interesse pelos conteúdos relacionados com os exergames.

Figura 5 - Quantitativo de alunos que responderam pré e pós-intervenção pedagógica quais atividades gostariam que as aulas de Educação Física tivessem. 
ARAÚJO, J. dos S.; SOUZA, W. L. de; SOUZA, A. A. de; SANTOS, J. C. dos; RIBEIRO, J. de C.; BRITO, A. F. de
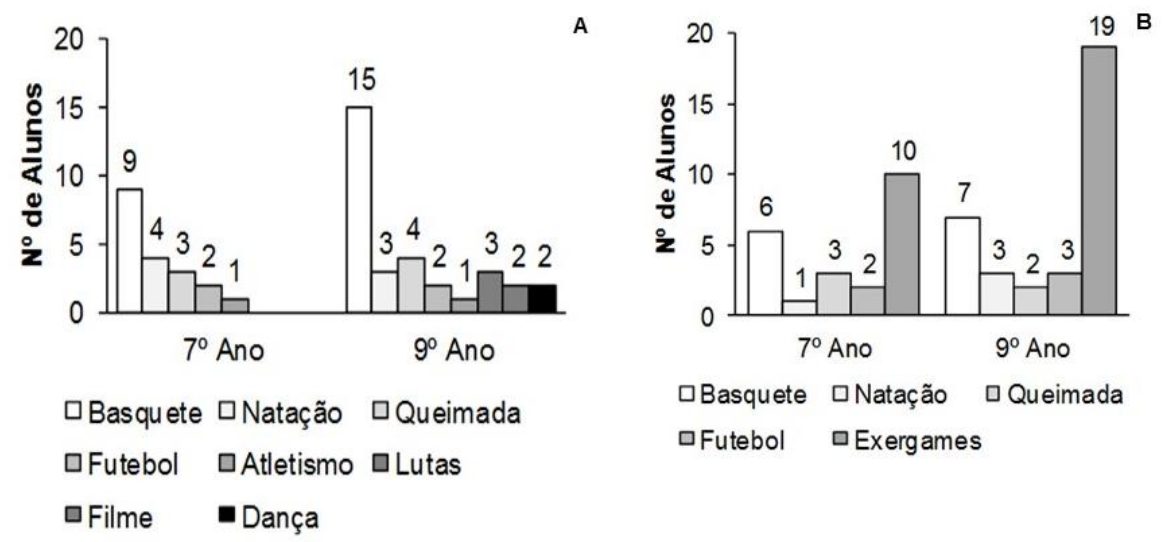

Períodos pré (painel A) e pós-intervenção pedagógica (painel B). Os dados estão apresentados como valores percentuais.

Fonte: própria autoria.

\section{Discussão}

O presente estudo tem como objetivo verificar se a utilização dos exergames colabora para a motivação de participação em aulas de Educação Física escolar na cidade de TeresinaPI. Tomados em conjunto, os dados apontam que os alunos se sentiram motivados a utilizar os exergames nas aulas de Educação Física e que essa modalidade de jogos eletrônicos pode ser uma nova estratégia para se vivenciarem práticas corporais e esportivas que dificilmente seriam abordadas nas aulas tradicionais de Educação Física escolar, como o boliche, o boxe e algumas provas do atletismo.

Os ambientes virtuais de aprendizagem (AVAs) têm se disseminado nas diversas áreas do conhecimento e contribuído com a dinamização e motivação para a participação nas aulas de Português e Matemática (VAGHETTI; BOTELHO, 2010; VAGHETTI; VIEIRA; BOTELHO, 2016). Nesse sentido, novas metodologias para o processo de ensinoaprendizagem têm sido desenvolvidas a partir dos AVAs, de modo a contribuir com o enriquecimento de informações e conhecimentos (CAPARROZ; LOPES, 2008), inclusive ancorados pelo texto da nova Base Nacional Comum Curricular (BNCC) (BRASIL, 2017).

Assim, no ambiente escolar, é possível verificar que alguns games educativos são utilizados para aprimoramento da cognição, tomadas de decisão e lógica (OBLINGER, 2004; BRASIL, 2017), como Simon (memória), Laranja Calculadora (matemática), Train Game (formas geométricas) e o Alphabetical Wack a Mole (linguagem). Embora os AVAs sejam um importante meio de desenvolvimento intelectual, ainda não é possível observar como eles 
poderiam contribuir com a parte motora da criança, do adolescente ou adulto para esse público e local em específicos.

Alguns estudos (LANNINGHAM-FOSTER, 2006; GRAVES et al., 2010) têm relatado o aumento da frequência cardíaca e do nível de atividade física durante a utilização de exergames em crianças com idades entre 8 e 12 anos e jovens de 13 a 16 anos. Sendo assim, nota-se que os exergames são utilizados sempre no segmento da saúde, enquanto o contexto pedagógico, mais especificamente voltado para a Educação Física, ainda está em um processo inicial de imersão nessas novas tecnologias. Vaghetti e Botelho (2006) e Vaghetti, Vieira e Botelho (2016) referem que os videogames, em especial os exergames, podem ser uma nova ferramenta pedagógica utilizada para a disseminação dos conhecimentos tecnológicos capazes de proporcionar ganhos de ordem sensorial e motora, além de auxiliarem na promoção da atividade física, propiciada pelo mecanismo de realidade virtual. Essa lógica educacional entra em consonância com o preconizado pela BNCC (2017) em evolução aos textos dos PCNs (1996).

Baracho, Gripp e Lima (2012) realizaram um estudo com alunos de 13 e 14 anos com a finalidade de analisar as perspectivas de utilização dos jogos virtuais em uma escola pública de Diamantina, Minas Gerais. Para tanto foi escolhido o jogo virtual de beisebol para ser comparado com o real. Como resultado verificou-se que os estudantes apreciaram a partida de jogo virtual, embora a passividade e a inatividade desse jogo sejam importantes críticas negativas. As características positivas seriam a diversão, originalidade e diferença com o conteúdo abordado cotidianamente na escola. Quanto ao jogo real, determinaram como sendo uma prática de baixo êxito e cansativa.

Outro fator importante a ser ressaltado como encorajador para a práticas dos exergames envolve a motivação para a participação, pois, nesse tipo de jogo, os participantes podem alcançar a vitória, receber medalhas, quebrar recordes, mudar de fase, e subir ao pódio (KENSKI, 1995). Além disso, o ambiente é considerado não ameaçador, ou seja, os alunos retraídos, que se sentem mal ao participarem das aulas de Educação Física comuns, encontram, no espaço virtual, um meio para se aprimorarem, principalmente os que têm problemas coordenativos e funcionais (DALEY, 2010). Corroborando esses dados, no presente estudo, após a intervenção pedagógica, foi unânime o interesse dos alunos pelos exergames, contudo, não se pode afirmar por quais motivos houve essa motivação para a prática, considerando que opiniões mais detalhadas dos alunos não foram registradas. 
ARAÚJO, J. dos S.; SOUZA, W. L. de; SOUZA, A. A. de; SANTOS, J. C. dos; RIBEIRO, J. de C.; BRITO, A. F. de

Assim, em nosso estudo fica evidente que os exergames constituem ferramenta atrativa para as aulas de Educação Física, entretanto ressalta-se que a troca do exercício físico e do jogo real pelo virtual não deve ser precipitada, uma vez que os exergames podem ser incluídos como aulas motivadoras, mas não frequentemente, pois a escola ainda é um lugar de convívio e desenvolvimento das relações interpessoais, o que, frequentemente, não ocorre nos ambientes virtuais, mesmo nos mais ativos. A própria BNCC traz a possibilidade da utilização de novas tecnologias de aprendizagem para o desenvolvimento das competências gerais dos alunos (BRASIL, 2017, p. 9), para a área de linguagens (BRASIL, 2017, p. 63-65) e para a especificidade da Educação Física (BRASIL, 2017, p. 213) sem que, contudo, substituam as práticas corporais tradicionais (BRASIL, 2017, p. 214).

Como observado nos relatos dos alunos e na organização do planejamento pedagógico da professora regente da disciplina de Educação Física na escola, os jogos praticados durante as aulas eram sempre os mesmos, sendo a escolha da maioria o futsal, e os demais alunos eram agrupados para jogarem queimada. Para Darido (2005), o jogo como conteúdo escolar há muito tempo se faz presente na escola, mas se restringe somente ao fazer, não havendo a preocupação em estudar os seus valores e significados, em analisá-lo como um patrimônio cultural e ferramenta capaz de aprimorar o repertório motor, além de ser um elemento de transversalidade das disciplinas escolares. Embora seja possível observar que a disposição para a prática dos dois jogos tenha características voluntárias e sigam os conceitos do que seria jogo, é interessante observar que não há diversificação e aprendizado de novos gestos motores, uma vez que em todas as aulas os alunos adotavam como jogo o futsal ou a queimada.

Além disso, os jogos, para Lara e Pimentel (2006) e Huizinga (1996), podem ser classificados de diferentes formas, com objetivos que também se diferenciam. Esses conteúdos são abordados nas disciplinas de "jogos e brincadeiras" e "recreação e lazer" ou naquelas com ementas e nomenclaturas semelhantes com a finalidade de fornecer ao futuro professor de Educação Física as fases conceitual, procedimental e atitudinal para que os conteúdos de suas aulas sejam os mais diversificados possíveis e atraiam a atenção de seus alunos. Somado a isso, é durante os jogos e brincadeiras que as crianças encontram um importante meio para desenvolvimento de suas relações interpessoais e aprimoramento de suas capacidades físicas. 
Corroborando essa reflexão, Chicati (2000) realizou investigação com o objetivo de analisar quais são os fatores desmotivadores nas aulas de Educação Física escolar para alunos do ensino médio da cidade de Maringá, Paraná. A autora verificou, então, que a maioria dos professores, de fato, adotava conteúdos repetitivos, ademais de haver problemas no espaço físico escolar, como ambiente impróprio para a prática esportiva e materiais inadequados ou defasados.

É fato que, atualmente, $58 \%$ dos brasileiros têm acesso à internet e que 82,1\% jogam videogame em smartphones, os quais seguem o mesmo padrão de atratividade citado nos parágrafos anteriores. Logo, nota-se que a internet e os jogos virtuais são uma realidade e que as instituições de ensino superior responsáveis por formar os futuros professores, além das escolas, podem acompanhar essas modificações ocorridas na sociedade de modo a aprimorar seus currículos e conteúdos, sejam eles para memória, raciocínio lógico, Português, Matemática ou Educação Física.

O trabalho ainda é limitado devido aos poucos estudos encontrados, principalmente na região Nordeste e, mais especificamente, no Piauí, mas é evidente que os professores de Educação Física precisam estar abertos ao novo e necessitam de capacitações e estudos de aprimoramento sobre o uso das tecnologias digitais, pois elas se encontram presentes no dia a dia de muitos dos seus alunos.

Um dado que chama a atenção é a adesão completa dos alunos do $9^{\circ}$ à possibilidade de aulas com jogos eletrônicos (Figura 3). Sobre isso, há uma discrepância entre o anseio dos alunos e a BNCC, na qual, embora o trato do jogo seja apontado como ferramenta pedagógica, a sistematização de seu estudo na Educação Física - incluindo os jogos eletrônicos - não aparece como conteúdo para o $9^{\circ}$ ano, o que antes estava proposto pelos PCNs, o que pode configurar involução pedagógica e inadequação curricular contemporânea. Em contrapartida, para o $7^{\circ}$ ano, o conteúdo "brincadeiras e jogos" é preconizado pela BNCC, o que, por si só, parece não garantir que os alunos tenham contato com os jogos eletrônicos na escola, como mostra o resultado apresentado na Figura 4 para a pergunta em questão.

O contato com novas possibilidades de ferramentas pedagógicas - entre elas os jogos eletrônicos - é incentivado pela BNCC, trazendo a "experimentação" como uma das oitos dimensões do conhecimento (BRASIL, 2017, p. 220), parecendo essa ser determinante para que os alunos se apropriem ou não de novos conhecimentos e formas de linguagem, como 
ARAÚJO, J. dos S.; SOUZA, W. L. de; SOUZA, A. A. de; SANTOS, J. C. dos; RIBEIRO, J. de C.; BRITO, A. F. de

mostram os resultados da quinta pergunta traduzidos na Figura 5. Essa relação evidencia a escola como lócus determinante de contato com a modernidade para muitos dos alunos.

\section{Conclusão}

Tomados em conjunto, os dados do presente estudo demonstram que, em uma escola da cidade de Teresina-PI, os exergames foram responsáveis pelo aumento significativo da participação dos alunos de $7^{\circ}$ e $9^{\circ}$ anos do ensino fundamental nas aulas de Educação Física. Além disso, os jogos virtuais foram bem aceitos enquanto proposta educativa a ser utilizada durante as aulas de Educação Física.

Desse modo, compreendemos que a Educação Física escolar pode se apropriar das tecnologias digitais para ressignificar as aulas, proporcionando um novo olhar sobre as práticas corporais para os estudantes. Torna-se fundamental, no entanto, que os professores de Educação Física busquem formações e se atualizem quanto à utilização desses recursos que estão adentrando cada vez mais o ambiente escolar.

Assim, sugerimos que outros estudos possam ser realizados com a temática dos jogos eletrônicos (exergames) como proposta educativa nas aulas de Educação Física.

\section{Referências}

ALLEN, N. E. et al. An interactive videogame for arm and hand exercise in people with Parkinson's disease: A randomized controlled trial. Parkinsonism \& Related Disorders, $n$. 41, p. 66-72, 2017.

ANDRADE, T. E.; TASSA, KOME. Motivação nas aulas de Educação Física no ensino médio. Revista Digital Buenos Aires, v. 20, n. 203, p. 1-7, 2015.

BARBIER, R. A Pesquisa-Ação. Trad. Lucie Didio. Brasília: Liber Livro Editora, 2007.

BARACHO, A. F. O.; GRIPP, F. J.; LIMA, M. R. Os Exergames e a Educação Física Escolar na Cultura Digital. Revista Brasileira de Ciências do Esporte, v. 34, n. 1, p. 111-126, 2012.

BEHM-MORAWITZ, E.; LEWALLEN, J.; CHOI, G. A Second Chance at Health: How a 3D Virtual World Can Improve Health Self-Efficacy for Weight loss Management Among Adults. Cyberpsychology, Behavior and Social Networking, v. 19, n. 2, p. 74-79, 2006.

BRASIL. Secretaria da Educação Básica. Base Nacional Comum Curricular. Brasília, 2017. Disponível em:

http://portal.mec.gov.br/index.php?option=com_docman\&view=download\&alias=79601- 
anexo-texto-bncc-reexportado-pdf-2\&category_slug=dezembro-2017 pdf\&Itemid=30192. Acesso em: 8 dez. 2020.

BRASIL. Secretaria de Educação Fundamental. Parâmetros Curriculares Nacionais: Educação Física - Brasília (Brasil): MEC/SEF; 1997.

CAPARRÓZ, A. S. C.; LOPES, M. C. P. Desafios e perspectivas em ambientes virtuais de aprendizagem: inter-relações, formação tecnológica e prática docente. Educação, Formação e Tecnologias, v. 1, n. 2, p. 50-58, 2008.

CHICATI, K. C. Motivação nas aulas de educação física no ensino médio. Revista da Educação Física, v. 11, n. 1, p. 97-105, 2000.

COLLADO-MATEO, D. et al. Effects of Exergames on Quality of Life, Pain, and Disease Effect in Women with Fibromyalgia: a randomized controlled trial. Archivos Physiscal Medicine Rehabil, v. 98, n. 9, p. 1725-1731, 2017 b.

COLLADO-MATEO, D. et al. Exergames for women with fibromyalgia: a randomised controlled trial to evaluate the effects on mobility skills, balance and fear of falling. Peer Journal, v. 20, n. 5, p. 3211, 2017a.

DALEY, A. J. Can exergaming contribute to improving physical activity levels and health outcomes in children? Pediatrics, v. 124, n. 2, p. 763-771, 2010.

DARIDO, S. C. Implicações para a Prática Pedagógica. Rio de Janeiro: Guanabara Koogan, p. 293, 2005.

GOMES, K. R. Possibilidades do uso do exergames na educação física. 2014. 105 f. Dissertação (Mestrado em Educação) - Universidade Federal Tiradentes, Sergipe, 2014.

GRAVES, L. E. et al. The physiological cost and enjoyment of Wii Fit in adolescents, Young adults, and older adults. Journal of Physical Activity \& Health, v. 7, n. 3, p. 393-401, 2010.

HAYES, E.; SILBERMAN, L. Incorporating vídeo games into physical education. Journal of Physical Education, Recreation \& Dance, v. 78, n. 3, p. 1-58, 2007.

HUIZINGA, J. Homo ludens: o jogo como elemento da cultura. São Paulo (SP): Perspectiva. 1996.

KENSKI, V. M. O impacto da mídia e das novas tecnologias de comunicação na educação física. Revista Motriz, v. 1, n. 2, p. 129-133, 1995.

KLOMPSTRA, L.; JAARSMA, T.; STRÖMBERG, A. Exergaming to increase the exercise capacity and daily physical activity in heart failure patients: a pilot study. BMC Geriatrics, v. 18, n. 14, p.119, 2014.

LANNINGHAM-FOSTER, L. et al. Energy expenditure of sedentary screen time compared with active screen time for children. Pediatrics, n. 118, p. 1831-1835, 2006. 
ARAÚJO, J. dos S.; SOUZA, W. L. de; SOUZA, A. A. de; SANTOS, J. C. dos; RIBEIRO, J. de C.; BRITO, A. F. de

LARA, L. M.; PIMENTEL, G. G. A. Resenha do Livro os Jogos e os Homens: a Máscara e a Vertigem, de Roger Caillois. Revista Brasileira de Ciência do Esporte, v. 27, n. 2, p. 179$185,2006$.

LIERBERMAN, D. A. What can we learn from playing interactive games? In: VORDERER, P.; BRYANT, J. (org.). Playing video games: Motives, responses, and consequences. 2006. p. 379-397.

OBLINGER, D. The next generation of educational engagement. Journal Interactive Media Education, n. 8, p. 1-18, 2004.

PATEL, V. L. et al. Cognitive and learning sciences in biomedical and health instructional design: a review with lessons for biomedical informatics education. Journal of Biomedical Informatics, n. 42, p. 176-197, 2009.

PIZANI, J. et al. (Des)motivação na educação física escolar: uma análise a partir da teoria da autodeterminação. Revista Brasileira de Ciências do Esporte v. 38, n. 3, p. 259-266, 2016.

TENÓRIO, J. G.; SILVA, C. L. O desinteresse dos estudantes pelas aulas de educação física em uma escola de ensino público do estado de Mato Grosso. Salusvita, v. 34, n. 1, p. 27-44, 2015.

TOKUYOCHI, J. H. et al. Retrato dos professores de Educação Física das escolas estaduais do estado de São Paulo. Revista Motriz, v. 14, n. 4, p. 418-428, 2008.

TRIPP, D. Pesquisa-ação: uma introdução metodológica. Educação e Pesquisa, v. 31, n. 3, p. 443-466, 2005.

VAGHETTI, C. A. O.; BOTELHO, S. S. C. Ambientes virtuais de aprendizagem na educação física: uma revisão sobre a utilização de Exergames. Ciências \& Cognição. v. 15, n. 1, p. 76$88,2010$.

VAGHETTI, C. A. O.; VIEIRA, K. L.; BOTELHO, S. S. C. Cultura digital e Educação Física: problematizando a inserção de Exergames no currículo. Revista Educação: Teoria e Prática, v. 26, n. 51, p. 3-18, 2016.

Recebido em: 26/03/2020

Revisado em: 24/12/2020

Aprovado em: 07/01/2021

Publicado em: 15/03/2021 